\title{
EFFECTS OF HEPARIN ON ALIMENTARY HYPERLIPEMIA. AN ELECTROPHORETIC STUDY ${ }^{1}$
}

\author{
BY FRANZ S. M. HERBST AND NANCY A. HURLEY \\ (From the Research Laboratories of the Department of Dermatology, Harvard Medical School \\ and the Massachusetts General Hospital, Boston 14, Mass.)
}

(Submitted for publication October 16, 1953; accepted February 10, 1954)

A few recent communications deal with electrophoretic observations concerning the effect of heparin on alimentary hyperlipemia. Nikkilä (1) found by moving boundary electrophoresis a decrease of beta-1 globulin and an increase in alpha-1 globulin after the injection of heparin. Rosenberg (2) and Fasoli (3) noted on paper electrophoresis an increase in the mobility of the beta lipoproteins which migrated in or near the alpha-2 globulin area. On the other hand, Spitzer (4) stated that administration of heparin does not alter the electrophoretic patterns of serum proteins in either fasting or lipemic dogs.

To obtain further information about the effect of heparin on the plasma proteins in alimentary hyperlipemia normal individuals were given a meal rich in fat and thereafter the electrophoretic pattern of the serum was studied both before and after the intravenous injection of heparin. Electrophoretic analysis was made by paper electrophoresis as well as by moving boundary electrophoresis. The results of these studies are described in this paper.

\section{MATERIALS AND METHODS}

Collection of blood. Ten ml. of blood were withdrawn from eight normal individuals in a fasting state, after which a meal was given consisting of one pint of heavy cream, $16 \mathrm{Gm}$. of cocoa and $32 \mathrm{Gm}$. of sugar. Four and one-half hours after the ingestion of the meal, another $10 \mathrm{ml}$. of blood were withdrawn and subsequently $50 \mathrm{mg}$. of heparin (Lederle) 'were injected intravenously. Fifteen minutes after the injection of heparin, $10 \mathrm{ml}$. of blood were taken again. The blood samples were allowed to clot at room temperature, then were centrifuged and the serum removed with a pipette.

Analytical methods. For paper electrophoresis the method of Grassmann and Hannig (5) was used. Serum in the amount of $0.02 \mathrm{ml}$. was placed on a paper strip (Whatman No. 1) and the electrophoresis chamber was

1 This investigation was supported by a research grant A-414(C2) from the National Institute of Arthritis and Metabolic Diseases, of the National Institutes of Health, Public Health Service. filled with sodium barbital-sodium acetate buffer of $\mathrm{pH}$ 8.6 and ionic strength 0.1 . Electrophoresis was carried out at 110 volts for a period of 12 hours in a room at constant temperature. In order to determine the relationship of the lipids to the protein fractions, two paper strips were used simultaneously in one chamber under identical experimental conditions. One paper strip was dried at $100^{\circ} \mathrm{C}$. and stained with Amidoblack $10 \mathrm{~B}$ for detection of proteins. The other one was dried at $37^{\circ} \mathrm{C}$. and stained with Sudan Black B according to the technique of Swahn (6) for the determination of lipids. Moving boundary electrophoresis was carried out in a Perkin-Elmer model 38 Tiselius electrophoresis apparatus, using a barbital-sodium citrate buffer of $\mathrm{pH} 8.6$ and ionic strength 0.1. Prior to electrophoresis, the serum was dialyzed for 12 hours in this buffer.

The turbidity of the plasma samples was determined according to the method of Geyer, Mann, and Stare (7), except that the difference between the reading for the sample and the blank was divided by 10 and expressed in units.

\section{RESULTS}

\section{Paper electrophoresis}

In the fasting state two distinct bands were found on the paper strips stained for lipids. One intensely stained band was present in the area of the beta globulin, corresponding to the beta-lipoproteins; the other, less intensely stained, was in the area of the alpha- 1 globulin, corresponding to the alpha-lipoproteins (Figure $1 \mathrm{~A}$ ).

The samples of serum taken four and one-half hours after the ingestion of the fat meal showed a third and new lipid band due to the chylomicra, near the starting line where the hyperlipemic serum had been placed on the paper strip (Figure 1 B).

In the samples obtained fifteen minutes after the intravenous administration of $50 \mathrm{mg}$. of heparin the following changes were observed. The lipid material near the starting line had disappeared; the lipid band normally present in the beta globulin area then appeared in the area of alpha- 2 or even alpha-1 globulin, and instead of the lipid band, 


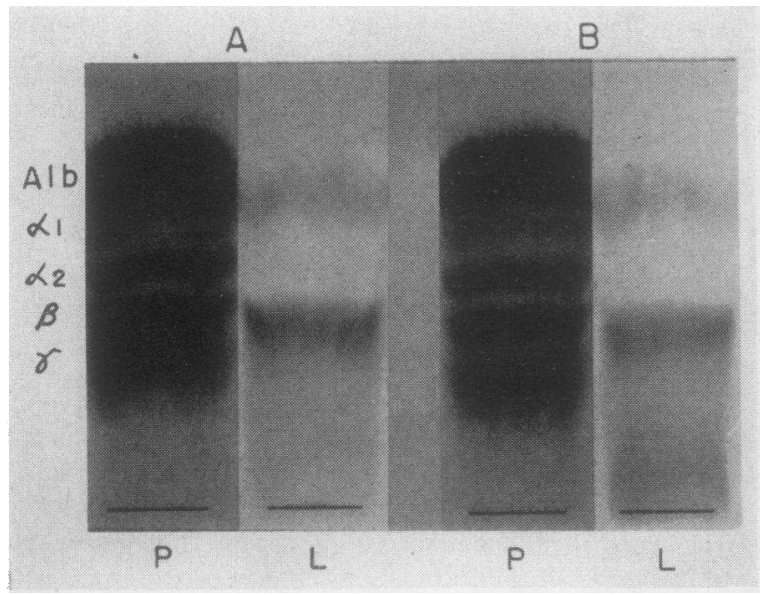

Fig. 1. Paper Electrophoretic Patterns of the Serum of a Normal Individual in a Fasting State (A) and in an Alimentary Hyperlipemic State (B)

The paper strips marked $\mathrm{P}$ are stained for proteins, those marked $\mathrm{L}$ are stained for lipids. In the fasting state (A) on the lipid stained paper strip (L) an intensely stained band is present in the beta globulin area and a less intensely stained band in the alpha-1 globulin area. In the alimentary hyperlipemic state (B) a new band is present on the lipid stained paper strip (L) near the starting line where the serum was placed.

normally present in the alpha-1 globulin area, lipid material migrated ahead of the albumin (prealbumin component) (Figure 2). The paper strips stained for proteins did not show any protein component ahead of the albumin. The relative values of the protein fractions of the sera taken during the fasting state, after the ingestion of fat and after the injection of heparin, showed no significant changes. The phenomena described above were observed in all eight cases studied.

\section{Moving boundary electrophoresis}

In the fasting state normal electrophoretic patterns were obtained in each of the eight cases. After the ingestion of the fat meal the serum became markedly turbid and it was therefore impossible to obtain satisfactory electrophoretic patterns in all eight cases. In the ascending pattern the albumin, alpha-1 and a part of the alpha-2 globulin peak were well visualized, while the rest of the pattern was rather faint and sometimes invisible. In the descending pattern the contrary occurred and the albumin, alpha- 1 and a part of the alpha-2 globulin peak were faint. This sug- gests that the chylomicra, which contribute largely to the turbidity, migrated with the approximate mobility of alpha-2 globulin and scattered the incident light intensively, causing incomplete exposure of the photographic film. After the injection of heparin, concomitant with the decrease in turbidity, this phenomenon was either absent or present to a much lesser degree, so that distinct patterns were obtained.

Because the patterns were severely obscured in three cases, calculation of the relative values of the protein fractions in the hyperlipemic sera was possible only in five cases. In the five cases the average of the relative values for alpha-1, alpha-2, and beta-1 globulin were slightly increased as compared with the values obtained during the fasting state. The alpha-1 globulins increased from 6.7 to 7.9 per cent, the alpha- 2 globulins from 8.3 to 9.4 per cent, and the beta- 1 globulins from 13.2 to 14.0 per cent of the total proteins (Table I).

After the injection of heparin the electrophoretic pattern was changed in all eight cases. There was a marked decrease in the size of the beta- 1 globulin peak together with an increase in the alpha-1 or alpha-2 globulin peak, or in both of them. In comparison with the fasting values, the beta-1 globulin was decreased from 13.2 to 8.6 per cent, and the alpha-2 globulin was increased from 8.3 to 9.9 per cent, and the alpha- 1 globulin increased from 6.7 to 9.0 per cent of the total proteins (Table I).

In the serum withdrawn after the injection no pre-albumin peak was seen on the photograph taken after the usual 55 minutes of electrophoresis. This was in contrast to the observations made by paper electrophoresis where a distinct pre-albumin component was present. This discrepancy was explained by studying the developing electrophoretic pattern. A pre-albumin peak appeared after 10 minutes, remained in the visual field for a maximum of 40 minutes and was no longer visible at 55 minutes (Figure 3). The mobility of the pre-albumin component was calculated in one case giving a value of $-9.8 \times 10^{-5} \mathrm{~cm}^{2}$./volt $\mathrm{sec}$ compared with a normal value of $-6.0 \times 10^{-5}$ $\mathrm{cm}^{2}$./volt sec for albumin. The pre-albumin component could, however, be demonstrated after 55 minutes of electrophoresis. This only occurred if the protein solution in the U-cell was not pushed 


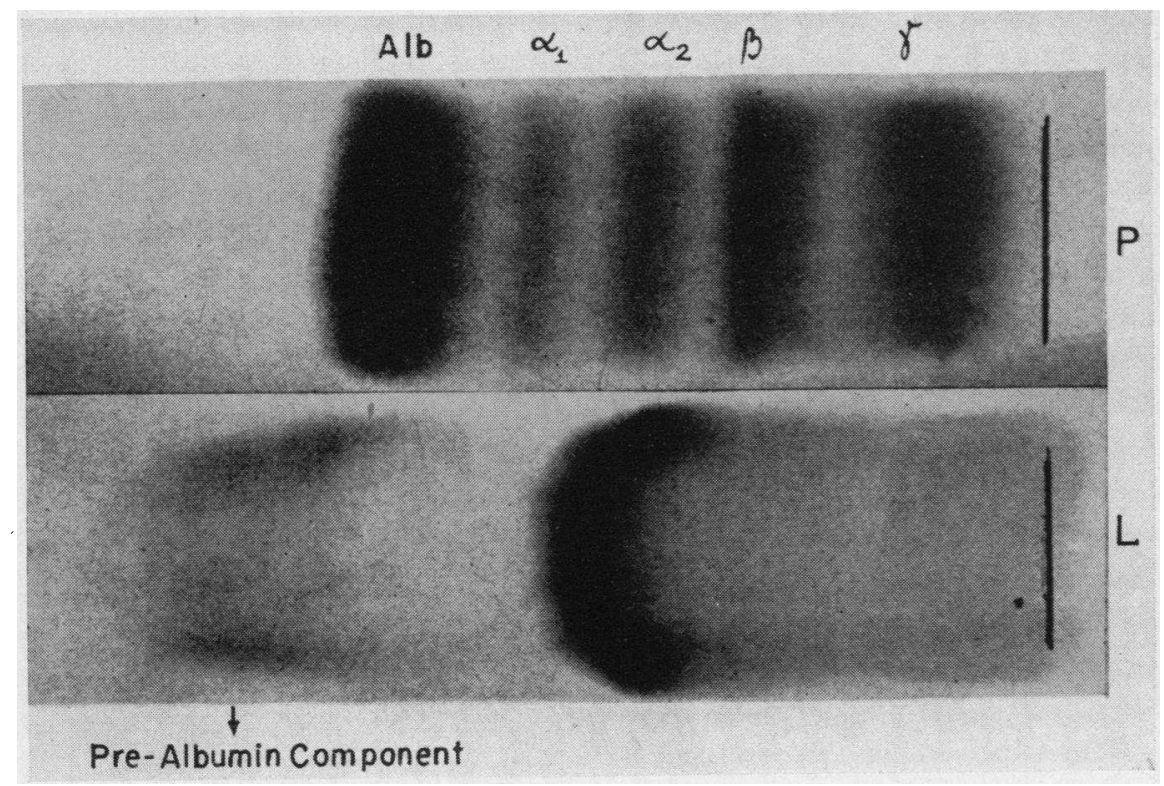

Fig. 2. Paper Electrophoretic Patterns of an Alimentary Hyperlipemic Serum after Injection of Heparin

$\mathrm{P}$ is stained for proteins, $\mathrm{L}$ is stained for lipids. On the lipid stained paper strip, a pre-albumin component can be seen and another lipid material in the alpha- 2 globulin area.

down by addition of buffer to make a visible boundary, as is usually done at the beginning of an electrophoretic experiment. In that case the protein fractions had to migrate a longer distance and, after 55 minutes, a pattern was obtained showing the various protein fractions including the prealbumin peak.

The relative concentration of the pre-albumin component was calculated from the electrophoretic patterns after 30 minutes. The values ranged from 3.4 to 7.9 per cent, averaging 5.6 per cent of the total concentration of the serum proteins.

\section{Turbidity}

The average turbidity values of the plasma increased after the ingestion of fat from the normal 3.0 units to 11.3 units, and decreased to 7.1 units fifteen minutes after the injection of heparin.

\section{Controls}

Control observations were made on five of the same persons, used in our studies. Heparin in the amount of $50 \mathrm{mg}$. was injected intravenously during the fasting state. In the paper electrophoresis no changes were found in the distribution of the

TABLE I

Average values of the serum protein fractions obtained on eight normal individuals by moving boundary electrophoresis*

\begin{tabular}{|c|c|c|c|c|c|c|c|c|}
\hline \multirow[b]{3}{*}{ State of serum } & \multicolumn{7}{|c|}{ Relative electrophoretic values in $\%$ of total protein } & \multirow{3}{*}{$\begin{array}{l}\text { Turbidity } \\
\text { of plasma } \\
\text { in units }\end{array}$} \\
\hline & \multirow{2}{*}{$\begin{array}{c}\text { Pre- } \\
\text { albumin } \\
\text { component }\end{array}$} & \multirow[b]{2}{*}{ Albumin } & \multicolumn{5}{|c|}{ Globulin } & \\
\hline & & & alpha-1 & alpha-2 & beta-1 & beta-2 & gamma & \\
\hline $\begin{array}{l}\text { Fasting } \\
\text { Hyperlipemic } † \\
\text { Post heparin }\end{array}$ & $\frac{\bar{z}}{5.6}$ & $\begin{array}{l}54.8 \\
51.1 \\
53.5\end{array}$ & $\begin{array}{l}6.7 \\
7.9 \\
9.0\end{array}$ & $\begin{array}{l}8.3 \\
9.4 \\
9.9\end{array}$ & $\begin{array}{r}13.2 \\
14.0 \\
8.6\end{array}$ & $\begin{array}{l}3.5 \\
3.3 \\
4.3\end{array}$ & $\begin{array}{l}13.6 \\
14.2 \\
14.3\end{array}$ & $\begin{array}{r}3.0 \\
11.3 \\
7.1\end{array}$ \\
\hline
\end{tabular}

* The values for the pre-albumin component are those obtained after 30 minutes, because at the end of the experiment ( 55 minutes) this component had migrated beyond the visual field.

$\dagger$ Average values of only five cases because the serum was too turbid in the other three to permit calculation. 


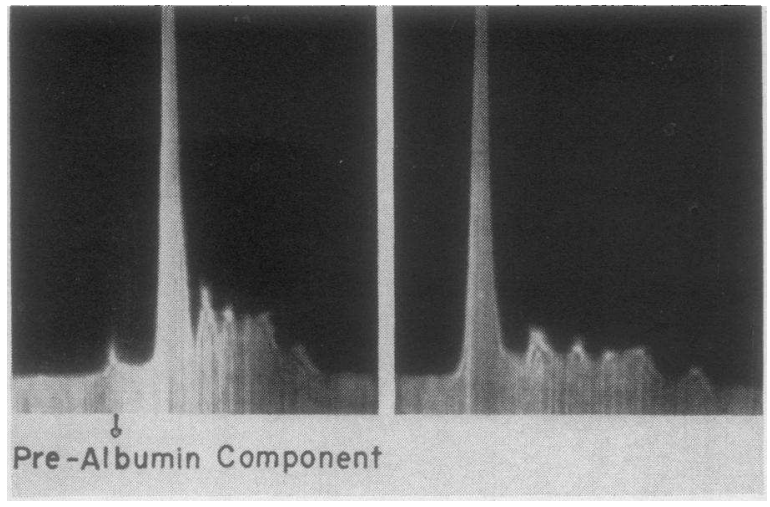

Fig. 3. Two Electrophoretic Patterns of an Alimentary Hyperlipemic Serum after Intravenous AdMINISTRATION OF HEPARIN

The photograph on the left was taken 30 minutes after the beginning of the experiment and shows the pre-albumin component. The photograph on the right was taken after 55 minutes when a pre-albumin component was no longer visible.

lipids among the protein fractions nor was any pre-albumin component observed, and the patterns obtained by moving boundary electrophoresis showed no significant changes of the protein fraction values. ${ }^{2}$

\section{DISCUSSION}

The most important result of the experiments was the detection of a pre-albumin component, not previously observed in alimentary hyperlipemia after the intravenous injection of heparin. Lever, Smith, and Hurley (8) had found a pre-albumin component, after the injection of heparin, in the fasting plasma of patients with idiopathic hyperlipemia. This pre-albumin component had a slower mobility than the one observed in this study, and it could be easily demonstrated after the normal duration of an electrophoretic experiment by the moving boundary electrophoresis.

In the present study the combined use of paper electrophoresis and moving boundary electrophoresis proved very satisfactory. In the Tiselius electrophoresis apparatus the presence of the pre-albumin peak might have been easily overlooked

2 This observation is at variance with a study reported from this laboratory (8) in which two of seven normal individuals had shown changes in their electrophoretic pattern following injection of heparin. It is possible that these two individuals had not been in a strictly fasting state. because of its fast migration, but it could be easily demonstrated on paper strips. Furthermore, the patterns on the paper strips represented specific color reactions, which gave also some information on the chemical nature of the separated fractions. However, from the fact that the pre-albumin component did not appear on the paper strips stained for proteins, one cannot conclude that protein was absent. The method is not sensitive enough to show very small quantities of protein.

That the pre-albumin component is not due to heparin itself is proved by the fact that the injection of $50 \mathrm{mg}$. of heparin during a fasting state never produced a component migrating ahead of the albumin. Hoch and Chanutin (9) and Blasius and Seitz (10) found that heparin itself formed a peak ahead of the albumin if large quantities of heparin were added to plasma in vitro. The concentration of heparin in the present experiments, however, was far too low to produce such a peak. Since the pre-albumin component was well stained with Sudan Black B, a dye specific for lipids, it is established that it contains a relatively large amount of lipids.

To explain the fast mobility of the pre-albumin component and the increase in the mobility of the beta-lipoproteins to that of the alpha globulins, one could assume that a combination of heparin with the lipoproteins occurred (8). Since heparin has a high negative electric charge it could cause an increase in the mobility of the complex toward the anode in the electric field. In such a case the question arises as to whether the $50 \mathrm{mg}$. of heparin which were injected, if combined with the total amount of circulating lipoproteins, would be enough to cause this phenomenon. Shore, Nichols, and Freeman (11) have shown that human plasma obtained after the intravenous administration of heparin has a lipolytic action, releasing fatty acids from lipoprotein molecules in vitro. Since by lipolysis smaller lipoprotein molecules are formed (12) this could contribute to the greater mobility of both lipoprotein classes. However, we did not see in our paper electrophoresis studies any significant increase in alpha-lipoproteins after action of heparin, as might be expected from the studies of Boyle, Bragdon, and Brown (13), indicating an enzymatic conversion of one lipoprotein class to another. Recently, Gordon, Boyle, Brown, Cherkes, and Anfinsen (14) stressed the role of 
serum albumin in the lipemia clearing reaction, namely the binding of fatty acids released during this reaction. Though fatty acids increase the mobility of albumin (15), the fast moving pre-albumin component is not due to a combination of albumin with fatty acids. In our experiments with paper electrophoresis, the pre-albumin component could be stained with lipid dyes, but not with protein dyes. In control experiments, however, fatty acids increased the speed of migration of pure albumin to a marked extent, but the fatty acid-albumin complex could only be stained by protein dyes and not by lipid dyes.

The electrophoretic changes, although effected by the injection of heparin, are probably not specific for heparin. Oncley and Gurd (16) observed an increase in the rate of electrophoretic migration in beta-lipoprotein preparations which had been stored for a long time. We found that storage of both fasting and hyperlipemic sera in a refrigerator at $5^{\circ} \mathrm{C}$. for three to four weeks gave paper électrophoretic patterns similar to those after an injection of heparin. On the paper strips stained for lipids a pre-albumin component was seen, and the beta-globulin lipid material migrated with the speed of the alpha globulins.

\section{SUM M ARY}

1. The effects of intravenously administered heparin on the plasma proteins and lipids in alimentary hyperlipemia were studied in eight normal individuals by paper electrophoresis and moving boundary electrophoresis.

2. After the injection of heparin analysis of the serum by paper electrophoresis with subsequent staining for proteins and lipids revealed that the lipid band, normally present in the beta globulin area, was then in the area of alpha- 2 or alpha-1 globulin. Instead of the lipid band, normally present in the alpha-1 globulin area, lipid material migrated ahead of the albumin.

3. Moving boundary electrophoresis showed a decrease in the beta- 1 globulins and an increase in the alpha-2 or alpha-1 globulins or both. A pre-albumin component was also observed.

\section{ACKNOWLEDGMENT}

The authors would like to express their appreciation to Dr. Walter F. Lever for advice and suggestions.

\section{REFERENCES}

1. Nikkilä, E. A., The effect of heparin on serum lipoproteins. Scandinav. J. Clin. \& Lab. Invest., 1952, 4, 369 .

2. Rosenberg, I. N., Serum lipids studied by electrophoresis on paper. Proc. Soc. Exper. Biol. \& Med., 1952, 80, 751.

3. Fasoli, A., Electrophoresis of serum lipoproteins on filter paper. Acta med. Scandinav., 1953, 145, 233.

4. Spitzer, J. J., Properties of heparin-produced lipemia clearing factor. Am. J. Physiol., 1952, 171, 492.

5. Grassmann, W., and Hannig, K., Ein quantitatives Verfahren zur Analyse der Serumproteine durch Papierelektrophorese. Hoppe Seyler's Ztschr. f. physiol. Chem., 1952, 290, 1.

6. Swahn, B., A method for localization and determination of serum lipids after electrophoretical separation on filter paper. Scandinav. J. Clin. \& Lab. Invest., 1952, 4, 98.

7. Geyer, R. P., Mann, G. V., and Stare, F. J., Parenteral nutrition. VI. Fat emulsions for intravenous nutrion: The turbidimetric determination of infused fat in blood after the intravenous administration of fat emulsions. J. Lab. \& Clin. Med., 1948, 33, 175.

8. Lever, W. F., Smith, P. A. J., and Hurley, N. A., Idiopathic hyperlipemia and primary hypercholesteremic xanthomatosis. III. Effect of intravenously administered heparin on the plasma proteins and lipids. J. Invest. Dermat., 1954, 22, 71.

9. Hoch, H., and Chanutin, A., Effects of anticoagulants on serum and plasma. J. Biol. Chem., 1952, 197, 503.

10. Blasius, R., and Seitz, W., Die Beeinflussung der elektrophoretischen Wanderungsgeschwindigkeit von Serumglobulinen durch Zusatz von Heparin. Klin. Wchnschr., 1952, 30, 905.

11. Shore, B., Nichols, A. V., and Freeman, N. K., Evidence of lipolytic action by human plasma obtained after intravenous administration of heparin. Proc. Soc. Exper. Biol. \& Med., 1953, 83, 216.

12. Brown, R. K., Boyle, E., and Anfinsen, C. B., The enzymatic transformation of lipoproteins. J. Biol. Chem., 1953, 204, 423.

13. Boyle, E., Bragdon, J. H., and Brown, R. K., Role of heparin in in vitro production of alpha lipoproteins in human plasma. Proc. Soc. Exper. Biol. \& Med., 1952, 81, 475.

14. Gordon, R. S., Jr., Boyle, E., Brown, R. K., Cherkes, A., and Anfinsen, C. B., Role of serum albumin in lipemia clearing reaction. Proc. Soc. Exper. Biol. \& Med., 1953, 84, 168.

15. Ballou, G. A., Boyer, P. D., and Luck, J. M., The electrophoretic mobility of human serum albumin as affected by lower fatty acid salts. J. Biol. Chem., 1945, 159, 111.

16. Oncley, J. L., and Gurd, F. R. N., The lipoproteins of human plasma, in Blood Cells and Plasma Proteins, edited by James L. Tullis, New York, N. Y., Academic Press Inc., 1953, p. 337. 